\title{
Reevaluation of Antioxidative Strategies for Birth Defect Prevention in Diabetic Pregnancies
}

\section{Zhiyong Zhao}

Department of Obstetrics, Gynecology and Reproductive Sciences, University of Maryland School of Medicine, Baltimore, Maryland, USA

\begin{abstract}
Diabetes mellitus in early pregnancy is the most severe maternal disease that is counted for $10 \%$ of newborn infants with structural defects. With the rapid increases in the number of diabetic women in childbearing age, the birth defect rate is projected to elevate dramatically. Thus, prevention of embryonic malformations becomes an urgent task. Animal studies have revealed an involvement of oxidative stress in diabetic embryopathy and treatment with antioxidants can reduce embryonic abnormalities. However, the failure of clinical trials using free radical-scavenging antioxidants to alleviate oxidative stress-related diseases prompts researchers to reevaluate the strategy in birth defect prevention. Hyperglycemia also disturbs other intracellular homeostasis, generating aberrant conditions. Perturbed folding of newly synthesized proteins causes accumulation of unfolded and misfolded proteins in the lumen of the endoplasmic reticulum (ER). The ER under the stress activates signaling cascades, known as unfolded protein response, to suppress cell mitosis and/or trigger apoptosis. ER stress can be ameliorated by chemical chaperones, which promote protein folding. Hyperglycemia also stimulates the expression of nitric oxide (NO) synthase 2 (NOS2) to produce high levels of $\mathrm{NO}$ and reactive nitrogen species and augment protein nitrosylation and nitration, resulting in nitrosative stress. Inhibition of NOS2 using inhibitors has been demonstrated to reduce embryonic malformations in diabetic animals. Therefore, targeting ER and nitrosative stress conditions using specific agents to prevent birth defects in diabetic pregnancies warrant further investigations. Simultaneously targeting multiple stress conditions using combined agents is a potentially effective and feasible approach.
\end{abstract}

Keywords: Birth defects; Diabetic embryopathy; Oxidative stress; Antioxidant; Endoplasmic reticulum stress; Nitrosative stress; Intervention

\section{Introduction}

Congenital fetal anomalies are a major factor in perinatal mortality and infant disability. According to the World Health Organization, approximately two hundred seventy thousand newborn babies die each year from congenital abnormalities [1]. In the United States, where perinatal care is widely available, still nearly one hundred fifty babies are born yearly having at least one structural birth defect $[2,3]$. The cause of the developmental malformations is multifactorial. It includes genetic factors (e.g., chromosomal abnormalities, gene mutations), maternal diseases (e.g., infection, diabetes mellitus), medications (e.g., valproic acid, methotrexate), and environmental toxins (e.g., tobacco smoke, alcohol consumption, pollutants) [2,3].

Diabetes mellitus in early pregnancies is the most severe maternal disease to cause birth defects in newborn infants, in addition to other adverse pregnant outcomes including small for gestational age (growth restriction), large for gestational age (macrosomia), and perinatal demise (spontaneous abortion, stillbirth) [4-8]. Although aggressive glycemic control and perinatal care are available in the developed countries, the birth defect rates in diabetic pregnancies remain much higher than the background rate $[5,6,9]$. The diabetic complication in pregnancy, known as diabetic embryopathy, is becoming more serious because the number of women of childbearing age with diabetes has been rapidly increasing, along with the climbing numbers of diabetics in the population [10]. Thus, prevention of birth defects from diabetic pregnancies has become an urgent task for basic researchers and clinical care-takers.

\section{Oxidative Stress and Antioxidative Approaches for Intervention}

It has been shown that maternal hyperglycemia alters mitochondrial morphology and function, leading to generate high levels of reactive oxygen species (ROS) [11,12]. Concurrently, hyperglycemia also reduces the levels of endogenous antioxidants, e.g., glutathione (GSH) and thioredoxin $[13,14]$ and suppresses the expression and activity of antioxidative enzymes, e.g., superoxide dismutases (SODs), GSH peroxidases, and catalase [15-17]. This imbalance between levels of oxygen free radicals and antioxidative buffering, known as oxidative stress, augments oxidation of proteins, lipids, and DNA, leading to perturbation of intracellular signaling, organelle function, and gene regulation, and ultimately decreased cell proliferation and increased programmed cell death (Figure 1) [18,19].

The identification of oxidative stress in diabetic embryopathy led to development of strategies to reduce fetal abnormalities using antioxidants in animal models (Figure 1). Lipoic acid (LA or $\alpha$-LA; an organosulfur compound) and vitamin $\mathrm{C}$ (VC; ascorbic acid) are hydrophilic free radical scavengers [20,21]. In diabetic pregnant animals, dietary supplementation of LA or VC has been shown to reduce embryonic malformation rate [22-25]. Vitamin $\mathrm{E}$ (VE; a-tocopherol) is a lipid-soluble antioxidant [26]. Treatment of diabetic pregnant animals with $\mathrm{VE}$ also lowers embryonic malformation rate [27-30]. N-acetylcysteine (NAC), a thiol-containing molecule, also

Corresponding author: Zhiyong Zhao, Department of Obstetrics, Gynecology and Reproductive Sciences, University of Maryland School of Medicine, Baltimore, Maryland, USA, Tel: 410+706-8401; E-mail: zzhao@fpi.umaryland.edu

Received December 17, 2015; Accepted February 02, 2016; Published February 12,2016

Citation: Zhao Z (2016) Reevaluation of Antioxidative Strategies for Birth Defect Prevention in Diabetic Pregnancies. J Biomol Res Ther 5: 145. doi:10.4172/21677956.1000145

Copyright: (c) 2016 Zhao Z. This is an open-access article distributed under the terms of the Creative Commons Attribution License, which permits unrestricted use, distribution, and reproduction in any medium, provided the original author and source are credited. 
Citation: Zhao Z (2016) Reevaluation of Antioxidative Strategies for Birth Defect Prevention in Diabetic Pregnancies. J Biomol Res Ther 5: 145. doi:10.4172/2167-7956.1000145

can scavenge ROS [31]. In diabetic pregnant rats, treatment with NAC decreases neural tube and heart defects in the embryos $[32,33]$. Some naturally occurring phytochemicals possess antioxidant properties and have been tested to reduce embryonic defects in pregnant animals. For example, administration of resveratrol to diabetic pregnant rats reduces oxidative state and embryonic malformation rate [34,35].

Increasing the expression of endogenous antioxdative enzymes may enhance the intracellular defense against hyperglycemic insult. It has been shown that, in strains of rat that express higher levels of SOD and catalase, embryos of diabetic dams are resistant to hyperglycemic insult [36]. In diabetic transgenic mouse models, over expression of SOD1 in embryos reduces malformation rate [37]. Therefore, strategies to upregulate the expression of antioxidative enzymes to reduce embryonic abnormalities warrant development (Figure 1).

Although animal studies have shown that antioxidants can reduce developmental malformations in embryos, the enthusiasm about the application to humans has been dampened by the failure in multiple large scale trials using antioxidants (VC, VE) to treat similar diseases (preeclampsia, cardiovascular diseases) [38-41]. The reason(s) for the ineffectiveness of the antioxidants are not known. It is speculated that existence of other cellular stress conditions may be a factor [41].

\section{Targeting Endoplasmic Reticulum Stress}

Indeed, stress in the endoplasmic reticulum (ER), exhibited by changes in specific factors (markers), in the embryos of diabetic animals has been observed [42-45]. Hyperglycemia disturbs the folding and processing of newly synthesized proteins. The unfolded and misfolded proteins are accumulated in the ER lumen, while the ER-associated protein degradation mechanism is impaired [46,47]. ER stress activates a number of molecular cascades, collectively known as the unfolded protein response (UPR), to upregulate chaperone proteins to resolve protein folding crisis, inhibit protein translation, suppress mitosis, and even trigger apoptosis (Figure 2) [48,49].

ER stress can be alleviated by enhancing protein folding, using chemical chaperones, including phenylbutyrate (PBA), ursodeoxycholic acid (UDCA), and taurine-conjugated derivative, tauroursodeoxycholic acid (TUDCA) (Figure 2). The chemical chaperones have been investigated in animal models and human diseases, such as cystic fibrosis and diabetes, and exhibited effectiveness in amelioration of the diseases [50-54]. PBA has been tested in mouse embryos cultured in high glucose and shown to reduce neural tube defects, making it a candidate for intervention in humans [45].

\section{Targeting Nitrosative Stress}

In addition to dysfunction of the ER, maternal hyperglycemia also stimulates production of nitric oxide (NO) in the embryo, notably in the central nervous and cardiovascular systems [55,56]. NO is a reactive radical and also reacts with ROS to generate more cytotoxic derivatives, such as peroxynitrite, known as reactive nitrogen species (RNS) $[57,58]$. These free radicals augment protein S-nitrosylation and nitration, generating a condition known as nitrosative stress (Figure 3) $[59,60]$. Under such stress condition, protein activity is altered and organelle function is perturbed, leading decreased cell mitosis and increased apoptosis (Figure 3) [61-63].

$\mathrm{NO}$ is produced by members of the NO synthase (NOS) family, consisting of NOS1 (neuronal NOS or nNOS), NOS2 (inducible NOS or iNOS), and NOS3 (endothelial NOS or eNOS) [64-66]. nNOS and eNOS are constitutively expressed and do not vigorously respond to

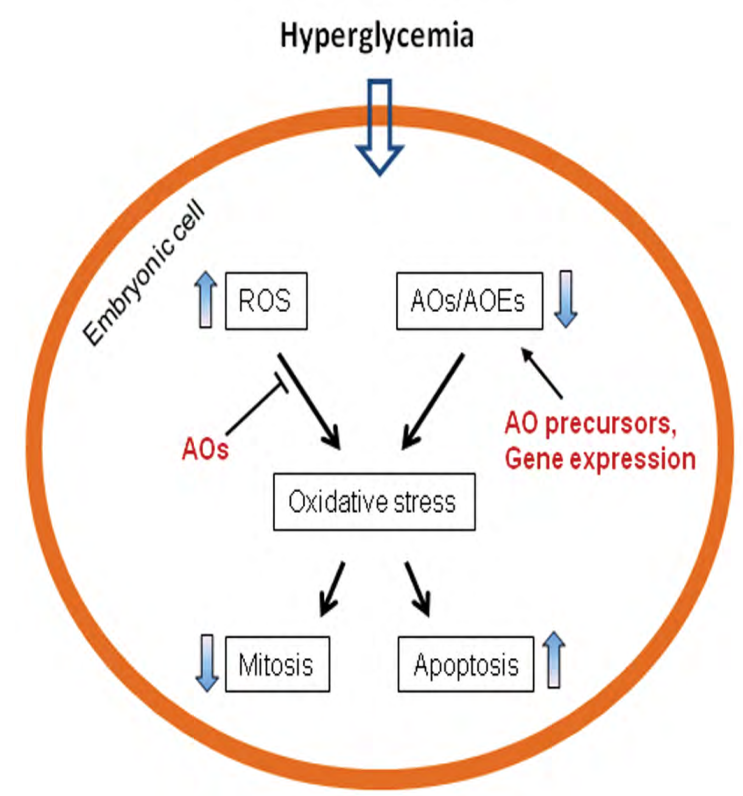

Figure 1: Oxidative stress in diabetic embryopathy. Hyperglycemia increases ROS (reactive oxygen species) and decreases AOs (antioxidants) and AOEs (antioxidative enzymes), leading to oxidative stress. To alleviate oxidative stress, AOs scavenge ROS, AO precursors increase the levels of endogenous $\mathrm{AOs}$, and upregulation of $\mathrm{AOE}$ gene expression enhances antioxidative capacity.

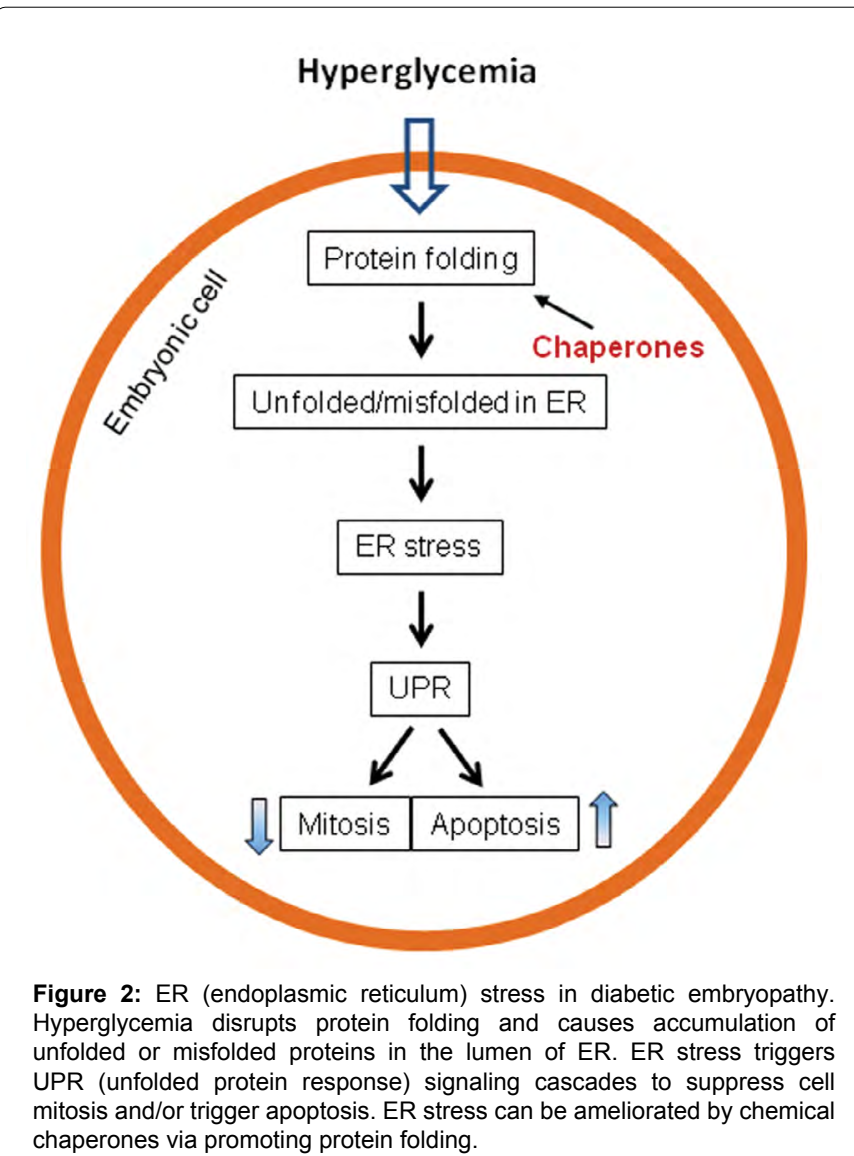




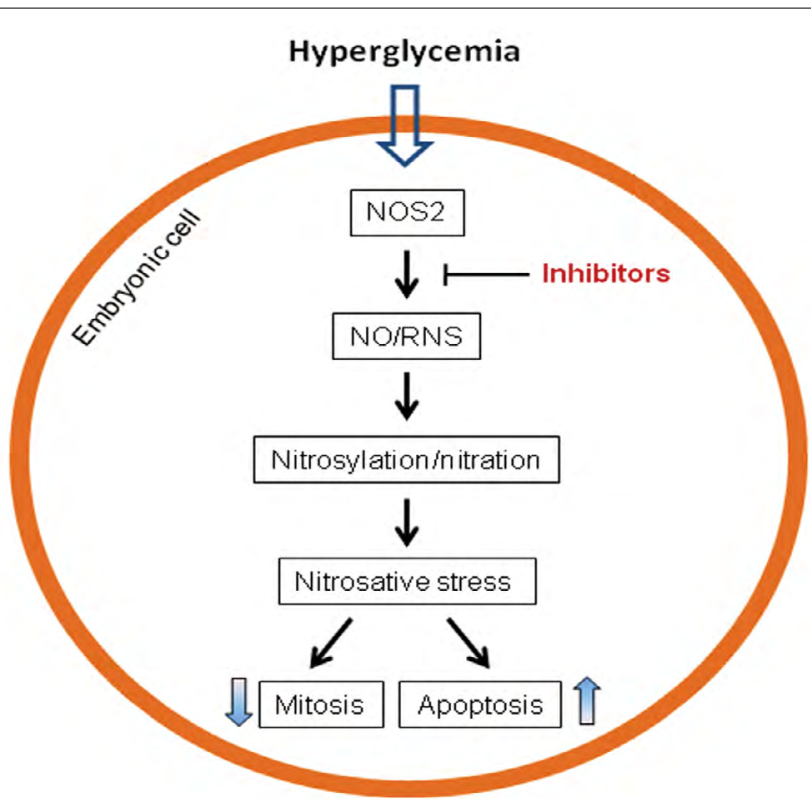

Figure 3: Nitrosative stress in diabetic embryopathy. Hyperglycemia stimulates the expression of NOS2 (nitric oxide synthase 2) to produce high levels of NO and RNS (reactive nitrogen species) and augment protein nitrosylation and nitration, resulting in nitrosative stress. Inhibition of NOS2 using inhibitors can ameliorate nitrosative stress.

extracellular stimulation $[67,68]$. NOS2, on the other hand, actively responds to extracellular and intracellular stimulation with marked upregulation in expression and activity [69-71].

In the embryos of diabetic animals, NOS2 expression is increased, whereas the expression of NOS1 and NOS3 is decreased [72,73]. The significance of NOS2 in diabetic embryopathy has been demonstrated using a nos2 gene knockout animal model, showing significant decreases in malformation rates in the brain and heart in the embryos lacking the gene [56]. Efforts to target NOS2 to alleviate nitrosative stress have been made and shown promising results, which oral treatment of diabetic pregnant animals with NOS2 inhibitors reduces embryonic malformation rates (Figure 3) $[43,56]$.

\section{New Strategies for Intervention in Diabetic Embryopathy}

The failure of antioxidant trials apparently casts clouds over the effort to apply the similar approach to birth defect prevention; but it also opens opportunities for developing new strategies. Instead of scavenging free radicals, reinforcing the endogenous antioxidative capacity is an approach potentially to achieve effectiveness. This approach includes upregulation of antioxidative enzymes and replenishing of endogenous antioxidants.

NAC, a cysteine precursor, and folic acid (FA), a methionine precursor, can increase biosynthesis of GSH to enhance intracellular protection against ROS [74,75]. Treatment with FA has been shown to decrease abnormalities in the embryos of diabetic animals [7678]. Retrospective clinical studies have shown the correlation of pre-conceptional FA intake with decreases in certain forms of fetal anomalies (neural tube defects) in diabetic pregnancies [79]. It is worth mentioning that the effect of FA on reduction of cardiac anomalies appears to be minimal $[79,80]$. The reason(s) for this are unknown, but it has been noticed that folate metabolism in diabetic pregnant women is not different from that in non-diabetic pregnant women [81].
In addition to the strategy of replenishing endogenous antioxidants, upregulation of antioxidative enzymes is also a powerful approach. This notion is supported by the experiments, in which overexpression of a superoxide dismutase in mouse embryos can decrease malformation rate in diabetic pregnancies [37,82]. Animal studies have shed lights onto these strategies. More work is needed to identify the effective and feasible agents to achieve the goals.

The embryos of diabetic pregnancies are under multiple cellular stress conditions (oxidative, ER, and nitrosative stresses). Each of the conditions can be intervened with pharmacological approaches in vivo (Figure 1). Targeting all the conditions simultaneously is potentially to be more effective to protect embryonic cells from maternal hyperglycemic insult. Treatments with cocktail of agents intervening different cellular signaling processes to reduce embryonic malformations in diabetic animals have shed lights on the feasibility of this approach [78,83-85]. With development of effective and safe agents for alleviating human intracellular stress conditions, prevention of birth defects in diabetic pregnancies will become reality using a combinational targeting approach.

\section{Acknowledgement}

Research work of author's group was supported by the Eunice Kennedy Shriver National Institute of Child Health \& Human Development of the National Institutes of Health under Award Numbers R01HD076245 and R03HD075995. The content is solely the responsibility of the author and does not necessarily represent the official views of the National Institutes of Health.

\section{References}

1. Liu L, Oza S, Hogan D, Perin J, Rudan I, et al. (2015) Global, regional, and national causes of child mortality in $2000-13$, with projections to inform post2015 priorities: an updated systematic analysis. Lancet 385: 430-440.

2. Yoon PW, Rasmussen SA, Lynberg MC, Moore CA, Anderka M, et al. (2001) The National Birth Defects Prevention Study. Public Health Rep 116: 32-40.

3. MacDorman MF, Gregory EC (2015) Fetal and Perinatal Mortality: United States, 2013. Natl Vital Stat Rep 64: 1-24.

4. Mills JL (1982) Malformations in infants of diabetic mothers. Teratology 25 385-394.

5. Correa A, Gilboa SM, Besser LM, Botto LD, Moore CA, et al. (2008) Diabetes mellitus and birth defects. Am J Obstet Gynecol 199: e231-239.

6. Zhao Z, Reece EA (2013) New concepts in diabetic embryopathy. Clin Lab Med 33: 207-233.

7. Mathiesen ER, Ringholm L, Damm $P$ (2011) Stillbirth in diabetic pregnancies. Best Pract Res Clin Obstet Gynaecol 25: 105-111.

8. Vitoratos N, Vrachnis N, Valsamakis G, Panoulis K, Creatsas G (2010) Perinatal mortality in diabetic pregnancy. Ann N Y Acad Sci 1205: 94-98.

9. Reece EA (2012) Diabetes-induced birth defects: what do we know? What can we do? Curr Diab Rep 12: 24-32.

10. CDC (2014) National Diabetes Statistics Report, 2014.

11. Yang X, Borg LA, Eriksson UJ (1995) Altered mitochondrial morphology of rat embryos in diabetic pregnancy. Anat Rec 241: 255-267.

12. Yang X, Borg LA, Eriksson UJ (1997) Altered metabolism and superoxide generation in neural tissue of rat embryos exposed to high glucose. Am J Physiol 272: E173-180.

13. Menegola E, Broccia ML, Prati M, Ricolfi R, Giavini E (1996) Glutathione status in diabetes-induced embryopathies. Biol Neonate 69: 293-297.

14. Sakamaki H, Akazawa S, Ishibashi M, Izumino K, Takino H, et al. (1999) Significance of glutathione-dependent antioxidant system in diabetes-induced embryonic malformations. Diabetes 48: 1138-1144.

15. Sivan E, Lee YC, Wu YK, Reece EA (1997) Free radical scavenging enzymes in fetal dysmorphogenesis among offspring of diabetic rats. Teratology 56: 343-349.

16. Weksler-Zangen S, Yaffe P, Ornoy A (2003) Reduced SOD activity and 
Citation: Zhao Z (2016) Reevaluation of Antioxidative Strategies for Birth Defect Prevention in Diabetic Pregnancies. J Biomol Res Ther 5: 145. doi:10.4172/2167-7956.1000145

increased neural tube defects in embryos of the sensitive but not of the resistant Cohen diabetic rats cultured under diabetic conditions. Birth Defects Res Part A Clin Mol Teratol 67: 429-437.

17. Wentzel P, Gareskog M, Eriksson UJ (2008) Decreased cardiac glutathione peroxidase levels and enhanced mandibular apoptosis in malformed embryos of diabetic rats. Diabetes 57: 3344-3352.

18. Loeken MR (2004) Free radicals and birth defects. J Matern Fetal Neonatal Med 15: 6-14.

19. Ornoy A (2007) Embryonic oxidative stress as a mechanism of teratogenesis with special emphasis on diabetic embryopathy. Reprod Toxicol 24: 31-41.

20. Bast A, Haenen GR (2003) Lipoic acid: a multifunctional antioxidant. Biofactors 17: 207-213.

21. Kojo S (2004) Vitamin C: basic metabolism and its function as an index of oxidative stress. Curr Med Chem 11: 1041-1064.

22. Cederberg J, Siman CM, Eriksson UJ (2001) Combined treatment with vitamin $\mathrm{E}$ and vitamin $\mathrm{C}$ decreases oxidative stress and improves fetal outcome in experimental diabetic pregnancy. Pediatr Res 49: 755-762.

23. Siman CM, Eriksson UJ (1997) Vitamin C supplementation of the maternal diet reduces the rate of malformation in the offspring of diabetic rats. Diabetologia 40: $1416-1424$

24. Al Ghafli MH, Padmanabhan R, Kataya HH, Berg B (2004) Effects of a-lipoic acid supplementation on maternal diabetes-induced growth retardation and congenital anomalies in rat fetuses. Mol Cell Biochem 261: 123-135.

25. Wiznitzer A, Ayalon N, Hershkovitz R, Khamaisi M, Reece EA, et al. (1999) Lipoic acid prevention of neural tube defects in offspring of rats with streptozocin-induced diabetes. Am J Obstet Gynecol 180: 188-193.

26. Mustacich DJ, Bruno RS, Traber MG (2007) Vitamin E. Vitam Horm 76: 1-21.

27. Reece EA, Wu YK, Wiznitzer A, Homko C, Yao J, et al. (1996) Dietary polyunsaturated fatty acid prevents malformations in offspring of diabetic rats. Am J Obstet Gynecol 175: 818-823.

28. Pinter E, Reece EA, Leranth CZ, Garcia-Segura M, Hobbins JC, et al. (1986) Arachidonic acid prevents hyperglycemia-associated yolk sac damage and embryopathy. Am J Obstet Gynecol 155: 691-702.

29. Sivan E, Reece EA, Wu YK, Homko CJ, Polansky M, et al. (1996) Dietary vitamin $E$ prophylaxis and diabetic embryopathy: morphologic and biochemical analysis. Am J Obstet Gynecol 175: 793-799.

30. Goldman AS, Baker L, Piddington R, Marx B, Herold R, et al. (1985) Hyperglycemia-induced teratogenesis is mediated by a functional deficiency of arachidonic acid. Proc Natl Acad Sci 82: 8227-8231.

31. Samuni Y, Goldstein S, Dean OM, Berk M (2013) The chemistry and biological activities of $\mathrm{N}$-acetylcysteine. Biochim Biophys Acta 1830: 4117-4129.

32. Wentzel P, Thunberg L, Eriksson UJ (1997) Teratogenic effect of diabetic serum is prevented by supplementation of superoxide dismutase and $\mathrm{N}$-acetylcysteine in rat embryo culture. Diabetologia 40: 7-14.

33. Moazzen H, Lu X, Ma NL, Velenosi TJ, Urquhart BL, et al. (2014) $\mathrm{N}$-Acetylcysteine prevents congenital heart defects induced by pregestational diabetes. Cardiovasc Diabetol 13: 1-13.

34. Singh CK, Kumar A, Hitchcock DB, Fan D, Goodwin R, et al. (2011) Resveratrol prevents embryonic oxidative stress and apoptosis associated with diabetic embryopathy and improves glucose and lipid profile of diabetic dam. Mol Nutr Food Res 55: 1186-1196.

35. Singh CK, Kumar A, LaVoie HA, DiPette DJ, Singh US (2012) Resveratro prevents impairment in activation of retinoic acid receptors and MAP kinases in the embryos of a rodent model of diabetic embryopathy. Reprod Sci 19: 949-961.

36. Cederberg J, Galli J, Luthman H, Eriksson UJ (2000) Increased mRNA levels of $\mathrm{Mn}-\mathrm{SOD}$ and catalase in embryos of diabetic rats from a malformation-resistant strain. Diabetes 49: 101-107.

37. Hagay ZJ, Weiss Y, Zusman I, Peled-Kamar M, Reece EA, et al. (1995) Prevention of diabetes-associated embryopathy by overexpression of the free radical scavenger copper zinc superoxide dismutase in transgenic mouse embryos. Am J Obstet Gynecol 173: 1036-1041.

38. Villar J, Purwar M, Merialdi M, Zavaleta N, Thi Nhu Ngoc N, et al. (2009)
World Health Organisation multicentre randomised trial of supplementation with vitamins $C$ and $E$ among pregnant women at high risk for pre-eclampsia in populations of low nutritional status from developing countries. $\mathrm{Br} \mathrm{J}$ Obstet Gynecol 116: 780-788.

39. Polyzos NP, Mauri D, Tsappi M, Tzioras S, Kamposioras K, et al. (2007) Combined vitamin $C$ and $E$ supplementation during pregnancy for preeclampsia prevention: a systematic review. Obstet Gynecol Surv 62: 202-206.

40. Briasoulis A, Tousoulis D, Antoniades C, Stefanadis C (2009) The oxidative stress menace to coronary vasculature: any place for antioxidants? Curr Pharm Des 15: 3078-3090.

41. Steinhubl SR (2008) Why have antioxidants failed in clinical trials? Am J Cardiol 101: 14D-19D.

42. Zhao Z (2012) Endoplasmic reticulum stress in maternal diabetes-induced cardiac malformations during critical cardiogenesis period. Birth Defects Res B Dev Reprod Toxicol 95: 1-6.

43. Zhao Z, Eckert RL, Reece EA (2012) Reduction in embryonic malformations and alleviation of endoplasmic reticulum stress by nitric oxide synthase inhibition in diabetic embryopathy. Reprod Sci 19: 823-831.

44. Cao Y, Zhao Z, Eckert RL, Reece EA (2012) The essential role of protein kinase $C \delta$ in diabetes-induced neural tube defects. J Matern Fetal Neonatal Med 25: 2020-2024.

45. Li X, Xu C, Yang P (2013) c-Jun NH2-terminal kinase $1 / 2$ and endoplasmic reticulum stress as interdependent and reciprocal causation in diabetic embryopathy. Diabetes 62: 599-608.

46. Stevens FJ, Argon Y (1999) Protein folding in the ER. Semin Cell Dev Biol 10 443-454.

47. Benyair R, Ron E, Lederkremer GZ (2011) Protein quality control, retention, and degradation at the endoplasmic reticulum. Int Rev Cell Mol Biol 292: 197-280.

48. Malhotra JD, Kaufman RJ (2007) The endoplasmic reticulum and the unfolded protein response. Semin Cell Dev Biol 18: 716-731.

49. Lai E, Teodoro T, Volchuk A (2007) Endoplasmic reticulum stress: signaling the unfolded protein response. Physiology 22: 193-201.

50. Kars M, Yang L, Gregor MF, Mohammed BS, Pietka TA, et al. (2010) Tauroursodeoxycholic Acid may improve liver and muscle but not adipose tissue insulin sensitivity in obese men and women. Diabetes 59: 1899-1905.

51. Roomans GM (2001) Pharmacological treatment of the ion transport defect in cystic fibrosis. Expert Opin Investig Drugs 10: 1-19.

52. Galietta LJ (2013) Managing the underlying cause of cystic fibrosis: a future role for potentiators and correctors. Paediatr Drugs 15: 393-402.

53. Ozcan U, Yilmaz E, Ozcan L, Furuhashi M, Vaillancourt E, et al. (2006) Chemical chaperones reduce ER stress and restore glucose homeostasis in a mouse model of type 2 diabetes. Science 313: 1137-1140.

54. Engin F, Yermalovich A, Nguyen T, Hummasti S, Fu W, et al. (2013) Restoration of the unfolded protein response in pancreatic $\beta$ cells protects mice against type 1 diabetes. Sci Transl Med 5: 211-156.

55. Jawerbaum A, Higa R, White V, Capobianco E, Pustovrh C, et al. (2005) Peroxynitrites and impaired modulation of nitric oxide concentrations in embryos from diabetic rats during early organogenesis. Reproduction 130 695-703.

56. Sugimura Y, Murase T, Oyama K, Uchida A, Sato N, et al. (2009) Prevention of neural tube defects by loss of function of inducible nitric oxide synthase in fetuses of a mouse model of streptozotocin-induced diabetes. Diabetologia 52: 962-971.

57. Pacher P, Beckman JS, Liaudet L (2007) Nitric oxide and peroxynitrite in health and disease. Physiol Rev 87: 315-424.

58. Szabo C, Ischiropoulos H, Radi R (2007) Peroxynitrite: biochemistry, pathophysiology and development of therapeutics. Nat Rev Drug Discov 6 662-680.

59. Hess DT, Matsumoto A, Kim SO, Marshall HE, Stamler JS (2005) Protein S-nitrosylation: purview and parameters. Nat Rev Mol Cell Biol 6: 150-166.

60. Ridnour LA, Thomas DD, Mancardi D, Espey MG, Miranda KM, et al. (2004) The chemistry of nitrosative stress induced by nitric oxide and reactive nitrogen oxide species. Putting perspective on stressful biological situations. Biol Chem 385: 1-10. 
Citation: Zhao Z (2016) Reevaluation of Antioxidative Strategies for Birth Defect Prevention in Diabetic Pregnancies. J Biomol Res Ther 5: 145. doi:10.4172/2167-7956.1000145

Page 5 of 5

61. Brune B (2003) Nitric oxide: NO apoptosis or turning it ON? Cell Death Differ 10: $864-869$

62. Kim KM, Kim PK, Kwon YG, Bai SK, Nam WD, et al. (2002) Regulation of apoptosis by nitrosative stress. J Biochem Mol Biol 35: 127-133.

63. Chung HT, Pae HO, Choi BM, Billiar TR, Kim YM (2001) Nitric oxide as a bioregulator of apoptosis. Biochem Biophys Res Commun 282: 1075-1079.

64. Knowles RG, Moncada S (1994) Nitric oxide synthases in mammals. Biochem J 298: 249-258.

65. Torreilles $\mathrm{J}$ (2001) Nitric oxide: one of the more conserved and widespread signaling molecules. Front Biosci 6: D1161-D1172.

66. Groves JT, Wang CC (2000) Nitric oxide synthase: models and mechanisms Curr Opin Chem Biol 4: 687-695.

67. Umar S, van der Laarse A (2010) Nitric oxide and nitric oxide synthase isoforms in the normal, hypertrophic, and failing heart. Mol Cell Biochem 333: 191-201.

68. Zhou L, Zhu DY (2009) Neuronal nitric oxide synthase: structure, subcellular localization, regulation, and clinical implications. Nitric Oxide 20: 223-230.

69. Hesslinger C, Strub A, Boer R, Ulrich WR, Lehner MD, et al. (2009) Inhibition of inducible nitric oxide synthase in respiratory diseases. Biochem Soc Trans 37: 886-891.

70. Kleinert H, Schwarz PM, Forstermann U (2003) Regulation of the expression of inducible nitric oxide synthase. Biol Chem 384: 1343-1364.

71. Kroncke KD, Suschek CV, Kolb-Bachofen V (2000) Implications of inducible nitric oxide synthase expression and enzyme activity. Antioxid Redox Signal 2: $585-605$.

72. Kumar SD, Yong SK, Dheen ST, Bay BH, Tay SS (2008) Cardiac malformations are associated with altered expression of vascular endothelial growth factor and endothelial nitric oxide synthase genes in embryos of diabetic mice. Exp Biol Med 233: 1421-1432.

73. Jawerbaum A, Gonzalez ET, Novaro V, Faletti A, Sinner D, et al. (1998) Increased prostaglandin $\mathrm{E}$ generation and enhanced nitric oxide synthase activity in the non-insulin-dependent diabetic embryo during organogenesis. Reprod Fertil Dev 10: 191-196.
74. Zafarullah M, Li WQ, Sylvester J, Ahmad M (2003) Molecular mechanisms of $\mathrm{N}$-acetylcysteine actions. Cell Mol Life Sci 60: 6-20.

75. Donnelly JG (2001) Folic acid. Crit Rev Clin Lab Sci 38: 183-223.

76. Wentzel P, Gareskog M, Eriksson UJ (2005) Folic acid supplementation diminishes diabetes- and glucose-induced dysmorphogenesis in rat embryos in vivo and in vitro. Diabetes 54: 546-553.

77. Oyama K, Sugimura Y, Murase T, Uchida A, Hayasaka S, et al. (2009) Folic acid prevents congenital malformations in the offspring of diabetic mice. Endocr J 56: 29-37.

78. Higa R, Kurtz M, Mazzucco MB, Musikant D, White V, et al. (2012) Folic acid and safflower oil supplementation interacts and protects embryos from maternal diabetes-induced damage. Mol Hum Reprod 18: 253-264.

79. Banhidy F, Dakhlaoui A, Puho EH, Czeizel AA (2011) Is there a reduction of congenital abnormalities in the offspring of diabetic pregnant women after folic acid supplementation? A population-based case-control study. Congenit Anom 51: $80-86$.

80. Czeizel AE, Bartfai Z, Banhidy F (2011) Primary prevention of neural-tube defects and some other congenital abnormalities by folic acid and multivitamins: history, missed opportunity and tasks. Ther Adv Drug Saf 2: 173-188.

81. Kaplan JS, Iqbal S, England BG, Zawacki CM, Herman WH (1999) Is pregnancy in diabetic women associated with folate deficiency? Diabetes Care 22: 1017 1021

82. Li X, Weng $\mathrm{H}$, Reece EA, Yang $\mathrm{P}$ (2011) SOD1 overexpression in vivo blocks hyperglycemia-induced specific PKC isoforms: substrate activation and consequent lipid peroxidation in diabetic embryopathy. Am J Obstet Gynecol 205: e81-e86.

83. Reece EA, Wu YK, Zhao Z, Dhanasekaran D (2006) Dietary vitamin and lipid therapy rescues aberrant signaling and apoptosis and prevents hyperglycemiainduced diabetic embryopathy in rats. Am J Obstet Gynecol 194: 580-585

84. Reece EA, Wu YK (1997) Prevention of diabetic embryopathy in offspring of diabetic rats with use of a cocktail of deficient substrates and an antioxidant. Am J Obstet Gynecol 176: 790-797.

85. Gareskog M, Eriksson UJ, Wentzel P (2006) Combined supplementation of folic acid and vitamin $E$ diminishes diabetes-induced embryotoxicity in rats. Birth Defect Res A Clin Mol Teratol 76: 483-490. 